\title{
Measurement of Parotid Gland Volume in A symptomatic Adult Sudanese Population using Ultrasonography
}

Mohammed Amir Hassan ${ }^{1 *}$, Awadia Gareeballah Suliman ${ }^{1,2}$, Ahmed Abdelrahim Mohammed ${ }^{1}$, Maisa Mohammed Elzaki $^{1,2}$, Hanan Elnour ${ }^{1,3}$, Rihab Ali Yousif ${ }^{1}$

\author{
${ }^{1}$ Faculty of Radiological Sciences and Medical Imaging, Alzaiem Alazhari University, Khartoum, Sudan \\ ${ }^{2}$ Department of Diagnostic Radiologic Technology, Faculty of Applied Medical Sciences, Taibah University, Al-madinah Al-Munawarah, King Saudi \\ Arabia \\ ${ }^{3}$ Taif Universities, College of Applied Medical Sciences, Taif, KSA
}

DOI: $10.36347 /$ sjams.2020.v08i05.005

| Received: 26.04.2020 | Accepted: 03.05.2020 | Published: 06.05.2020

*Corresponding author: Mohammed Amir Hassan

Abstract

Original Research Article

This was cross sectional study done in Khartoum state Sudan in Alhikma Polyclinics in the period from 2018-2020, to measure parotid gland volume in a symptomatic Sudanese population by ultrasonography. The study done in 251 adult Sudanese in age ranged 18-53 years with mean age 30.63 years, after an ethical approval taken from each patient, high frequency ultrasound of parotid glands is performed, the data collected by data sheet then analyzed by SPSS (Statistical Package for Social Sciences). The study demonstrate that the mean parotid gland volume was $2.79 \mathrm{~cm}^{3}$ \pm 0.69 , right parotid is larger in volume than left, there was significant difference in mean volume in both gender ( $\mathrm{P}$ $<0.05)$, female had larger volume than male. There was positive strong significant association between age and parotid volume $(\mathrm{P}<0.01, \mathrm{r}=0.585)$.

Keywords: Ultrasound, Parotid, Volume, Adult, High frequency.

Copyright @ 2020: This is an open-access article distributed under the terms of the Creative Commons Attribution license which permits unrestricted use, distribution, and reproduction in any medium for non-commercial use (NonCommercial, or CC-BY-NC) provided the original author and source are credited.

\section{INTRODUCTION}

The parotid gland are major salivary glands that may affected by different diseases including neoplasm, inflammation which may cause hyperplastic or hypertrophic changes in the salivary glands $[1,2]$.

Ultrasonography (US) is first line in differential diagnosis of diseases of the salivary glands, may suggest final diagnosis or definite diagnose of others like sialolithiases. Many disorders occur in parotid gland and may cause decreased or increased in gland size so it's important to measure the gland size, no reference value for parotid gland measurements available for Sudanese adults and on literature. The paired parotid glands are the largest of the salivary glands. Each has an average weight of $25 \mathrm{~g}$ and is an irregular, lobulated, yellowish mass, lying largely below the external acoustic meatus between the mandible and sternocleidomastoid. The gland also projects forwards on to the surface of masseter. The overall shape of the parotid gland is variable. Viewed laterally, in half of cases it is roughly triangular in outline. Sometimes, however, the gland is of even width throughout, and the upper and lower poles are rounded. The average dimensions of the parotid duct are $5 \mathrm{~cm}$ long and $3 \mathrm{~mm}$ wide (although it is narrower at its oral orifice). It begins by the confluence of two main tributaries within the anterior part of the parotid gland; the duct appears at the anterior border of the upper part of the gland and passes horizontally across masseter, approximately midway between the angle of the mouth and the zygomatic arch [3].

The parotid gland is relatively fatty and appears homogeneously hyperechoic. It produces greater attenuation of sound than other soft tissues; it sometimes requires lower-frequency transducers than would otherwise be expected for such a superficial structure. Sound attenuation by parotid parenchyma explains the common finding of increased through transmission behind solid lesions. The parotid duct exits the anterior aspect of the gland and courses over the masseter muscle before diving through the buccinators muscle to terminate at an orifice lateral to the second upper molar [4].

\section{OBJECTIVE}

To assess the normal parotid gland volume in adult Sudanese using high frequency ultrasonography 


\section{METHODOLOGY}

This was cross sectional study done in Khartoum state Sudan in Alhikma OLYCLINICS 1 in the period from 2018 to 2020, the sampling includes 255 adult Sudanese population came to ultrasound department of other purpose of scanning rather than for salivary gland, after ethical approval was taken from each patients, ultrasound for parotid gland is performed using Ezoate mylap 40 with $7.5 \mathrm{MHz}$ high frequency linear array probe, the patient is examined in reclining position, neck extended, head slightly turned to the side opposite the glands being examined, both side are examine in longitudinal and transverse plane parallel and perpendicular to the submandibular plane, the gland appear glands have a homogeneous parenchyma when they are study by us, their echogenicity depends on the fat content of the gland, old people have a higher echogenicity, the size of parotid gland in both side is measured ( L, AP, Width and volume) as seen in figure (2), the data collected using data collection sheet including the study variables, then analyzed by SPSS version 16 , mean \pm Std. Deviation are performed then correlation was done to assess the variation of gland size in different gender and to correlate measurement with age ( $\mathrm{p}$ value $<0.05$ consider significant and > 0.05 consider insignificant)

\section{RESULTS AND DISCUSSION}

The age divided into five age group ranged from 18-53 years ,more than halve of them in age group $18-27$ years ( $57 \%$ ) followed by $38-47$ ( $24.3 \%$ ), the mean age was 30.63 years as shown in table (1).

Table-1: Age group distribution

\begin{tabular}{|l|l|l|l|l|}
\hline Age lyears & Frequency & Percent & Valid Percent & Cumulative Percent \\
\hline $18-27$ & 143 & 57.0 & 57.0 & 57.0 \\
\hline $28-37$ & 32 & 12.7 & 12.7 & 69.7 \\
\hline $38-47$ & 61 & 24.3 & 24.3 & 94.0 \\
\hline $48-53$ & 15 & 6.0 & 6.0 & 100.0 \\
\hline Total & 251 & 100.0 & 100.0 & \\
\hline
\end{tabular}

More than halve of patients were female $59.8 \%$, table (2).

Table-2: Gender distribution

\begin{tabular}{|l|l|l|l|l|}
\hline Gender & Frequency & Percent & Valid Percent & Cumulative Percent \\
\hline Female & 150 & 59.8 & 59.8 & 59.8 \\
\hline Male & 101 & 40.2 & 40.2 & 100.0 \\
\hline Total & 251 & 100.0 & 100.0 & \\
\hline
\end{tabular}

The study found that the mean measurement of parotid gland in a symptomatic Sudanese adult were $2.09 \pm 0.35 \mathrm{~cm}, 2.38 \pm 0.18 \mathrm{~cm}$ for length of right and left one respectively, $2.38 \pm 0.65,2.02 \pm 0.48$ for width respectively, $1.16 \pm 0.23$ and $1.07 \pm 0.33 \mathrm{~cm}$ for thickness right and left respectively, $2.95 \pm 0.94 \mathrm{~cm} 3$ and $2.62 \pm 0.78 \mathrm{~cm} 3$, the mean volume was $2.79 \pm 0.69$ $\mathrm{cm} 3$., this volume is slightly larger than in mention in literature 25 gram.(1) table (3)

Table-3: Descriptive statistic for measurements of parotid gland (minimum, maximum, mean \pm Std. Deviation

\begin{tabular}{|l|r|r|r|r|r|}
\hline Variables & $\mathbf{N}$ & Minimum & Maximum & Mean & Std. Deviation \\
\hline Age & 251 & 18 & 53 & 30.63 & 9.90 \\
\hline Length of right parotid & 251 & 1.7 & 3.0 & 2.09 & .35 \\
\hline Length of left parotid & 251 & 2.2 & 2.9 & 2.38 & .18 \\
\hline Width of right parotid & 251 & 1.0 & 3.0 & 2.38 & .65 \\
\hline Width of left parotid & 251 & .9 & 3.0 & 2.02 & .48 \\
\hline Thickness of right parotid & 251 & 1.0 & 2.9 & 1.16 & .23 \\
\hline Thickness of left parotid & 251 & .9 & 4.0 & 1.07 & .33 \\
\hline Volume of right parotid & 251 & 1.44 & 6.10 & 2.95 & .94 \\
\hline Volume of left parotid & 251 & 1.80 & 6.93 & 2.62 & .78 \\
\hline Mean parotid volume & 251 & 1.82 & 6.22 & 2.79 & .69 \\
\hline Valid N (listwise) & 251 & & & & \\
\hline
\end{tabular}

The study demonstrated there was significant difference in gland volume in different gender $(\mathrm{P}<0.05)$, female had larger parotid compare to male, the volume for female was $2.89 \pm 0.73 \mathrm{~cm}^{3}$ while for male $2.63 \pm$ $0.59 \mathrm{~cm}^{3}$, table (4). 
Table-4: Compare mean measurement of normal gland volume in different gender

\begin{tabular}{|l|l|c|r|r|r|c|}
\hline Volume & gender & $\mathbf{N}$ & Mean & Std. Deviation & Std. Error Mean & P value \\
\hline \multirow{2}{*}{ Right parotid volume } & Female & 150 & 3.07 & .96 & .078 & $<0.05$ \\
\cline { 2 - 7 } & Male & 101 & 2.77 & .89 & .089 \\
\hline \multirow{2}{*}{ Left parotid volume } & Female & 150 & 2.71 & .87 & .07 \\
\cline { 2 - 7 } & Male & 101 & 2.49 & .59 & .05 \\
\hline \multirow{2}{*}{ Mean volume } & Female & 150 & 2.89 & .73 & .06 \\
\cline { 2 - 6 } & Male & 101 & 2.63 & .59 & .05 & \\
\hline
\end{tabular}

Concerning correlation between age and volume of parotid strong significant positive correlation between mean gland size and age found $(r=0.585, \mathrm{p}<$ 0.01), table (5), this result similar to Se-Hwan Hwang et al whom stated that volume and size parameters of the PG were positively correlated with age $(p<0.05)[5]$.

Table-5: Correlation between age and volume

\begin{tabular}{|c|l|r|r|r|r|}
\hline \multicolumn{2}{|l|}{ Correlation } & age & Volume of right & Volume of left & Mean volume \\
\hline \multirow{3}{*}{ Age } & Pearson Correlation & 1 & $.667^{* * *}$ & $.236^{* * *}$ & $.585^{* * *}$ \\
\cline { 2 - 6 } & Sig. (2-tailed) & & .000 & .000 & .000 \\
\cline { 2 - 6 } & $\mathrm{N}$ & 251 & 251 & 251 & 251 \\
\hline
\end{tabular}

Moderate linear association was found between age and parotid volume, $\left(\mathrm{R}^{2}=0.3424\right)$, figure (1).

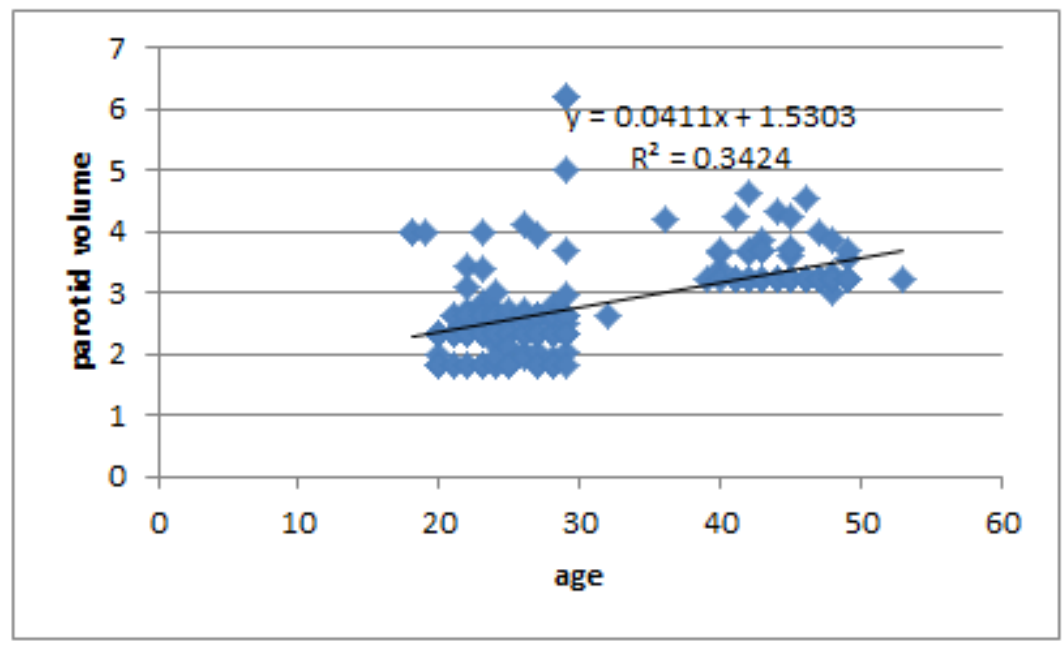

Fig-1: Shows linear relationship between age and parotid gland volume

The study demonstrate that significant differences in mean measurement of gland volume in different age group $(\mathrm{p}<0.01)$, the gland size increased with age and in almost all age group the right gland is larger in volume than in left except in age group 28-37 the left larger than the right, table (6), Wei Li et al. stated that the volumes of parotid glands increased with age [6].

Table-6: Compare means parotid gland volume $t$ in different age group

\begin{tabular}{|l|l|l|l|l|}
\hline Age & Right volume & Left volume & Mean volume \\
\hline \multirow{2}{*}{$18-27$} & Mean & 2.48 & 2.43 & 2.46 \\
\cline { 2 - 5 } & Std. Deviation & .66 & .66 & .45 \\
\hline \multirow{2}{*}{$28-37$} & Mean & 2.67 & 2.89 & 2.78 \\
\cline { 2 - 5 } & Std. Deviation & 1.22 & 1.33 & 1.12 \\
\hline \multirow{2}{*}{$38-47$} & Mean & 3.96 & 2.88 & 3.42 \\
\cline { 2 - 5 } & Std. Deviation & .26 & .60 & .35 \\
\hline \multirow{2}{*}{$48-53$} & Mean & 3.89 & 2.75 & 3.32 \\
\cline { 2 - 5 } & Std. Deviation & .27 & .22 & .21 \\
\hline \multirow{2}{*}{ Total } & Mean & 2.95 & 2.62 & 2.79 \\
\cline { 2 - 5 } & Std. Deviation & .94 & .78 & .69 \\
\hline P value & $0<0.001$ & \multicolumn{3}{|l}{} \\
\hline
\end{tabular}




\section{Conclusion}

The study concluded that mean parotid gland volume for adult Sudanese is $2.79 \mathrm{~cm}^{3} \pm 0.69$, parotid gland size increased significantly with age, the volume is larger in female than in male.

\section{RECOMMENDATIONS}

Further studies should be done adding other patient's factors (height, weight, BMI) for more accurate results.

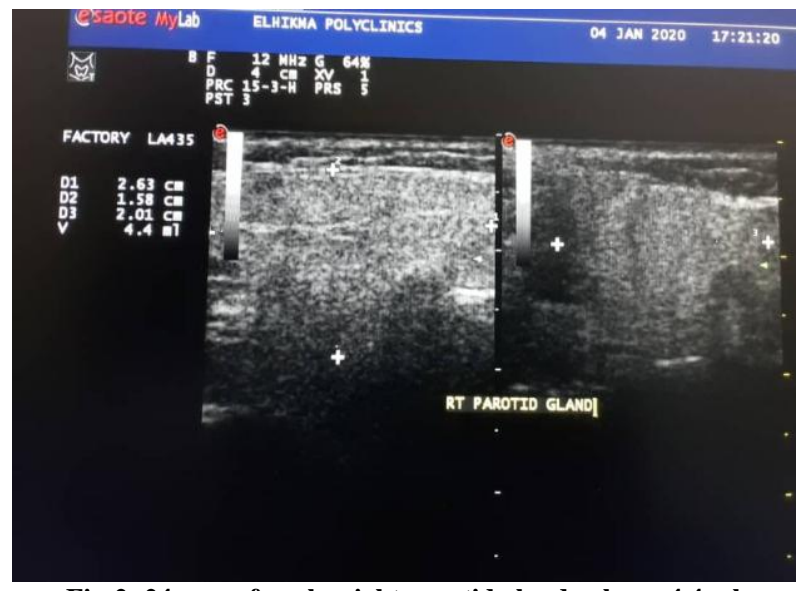

Fig-2: 24 years female, right parotid gland volume $4.4 \mathrm{ml}$ $(2.43 \times 1.58 \times 2.01 \mathrm{~cm})$

\section{REFERENCES}

1. Saito N, Sakai O, Bauer CM, Norbash AM, Jara H. Age-related relaxo-volumetric quantitative magnetic resonance imaging of the major salivary glands. J Comput Assist Tomogr. 2013;37(2):2728.

2. Ericson S, Hedin M. A clinical roentgenologic method of calculating the volume of the parotid gland. Oral Surg Oral Med Oral Pathol. 1970;29(4):536-43.

3. Susan Standring. Gray's Anatomy: The Anatomical Basis of Clinical Practice, forty first edition, 2016. Elsevier Limited. 978-0-7020-5230-9.

4. Barbara S. Hertzberg, William D. Middleton. Ultrasound: The Requisites, third Edition, 2016. Elsevier. 978-0-323-08618-9.

5. Se-Hwan Hwang, In-Jun Park, Yeon Min Jeong, Yeon Ji Lee, Jun-Myung Kang, Jae-Hyun Seo. Assessment of Age-Related Dimensions of the Salivary and Thyroid Glands Using ThreeDimensional Computed Tomography in Children. Korean J Otorhinolaryngol-Head Neck Surg. 2016;59(3):214-21.

6. Wei Li, Zhi-peng Sun, Xiao-jing, LIU, Guang -yan Yu. Volume Measurements of Human Parotid and Submandibular Glands. Beijing Da Xue Xue Bao Yi Xue Ban. 2014 Apr18; 46(2):288-93. 